Ann. Biol. anim. Bioch. Biophys., 1979, 19 (6), 1737-1744.

\title{
Rôle des ovaires maternels et des viscères fœtaux dans la synthèse et le méfabolisme des cestrogènes produits par le placenta de cobaye in vitro
}

\author{
par TRAN QUANG NHUAN, Marie-Elise GUY-MARTIN, G. L. ADESSI * \\ Laborafoire de Biochimie, U. E. R. des Saints Pères \\ 45, rue des Saints Pères 75006 Paris. \\ * Laboratoire de Biochimie, Faculté de Médecine et de Pharmacie \\ 4, Place Saint Jacques 25030 Besançon Cedex (France).
}

\begin{abstract}
Summary. Role of maternal ovaries and fetal viscera in the synthesis and metabolism of placental estrogens in vitro in the guinea-pig.

Placenta $(P)$, ovaries $(O)$, placenta plus ovaries $(P+O)$ and placenta plus fetal viscera $(P+F)$ of pregnant guinea-pigs were incubated with $\left[{ }^{3} \mathrm{H}\right]$-testosterone in vitro. Conversion into conjugated and unconjugated estrone and estradiol-17 $\beta$ was obtained in all incubated samples, except for the ovaries where only unconjugated estrogens were isolated. The percentage of conversion of $\left[{ }^{3} \mathrm{H}\right]$-testosterone to total estrogens was $P: 2 \mathrm{p} .100$, $O: 1.15$ p. $100, P+O: 2.01$ p. $100, P+F: 1.23$ p. 100, respectively. Estriol was formed from testosterone in only two of the six incubates of placenta plus fetal viscera, but the percentage of the total radioactivity isolated after TLC was less than 7 p. 1000 of the incubated radioactivity. Thus, during guinea-pig pregnancy, testosterone might serve as a precursor of conjugated and unconjugated estrone and estradiol-17 $\beta$ biosynthesis in the feto-placental compartment, and also in the ovary where unconjugated estradiol- $17 \beta$ was the predominant product.
\end{abstract}

\section{Introduction.}

L'hydroxylation en $C_{16}$ des cestrogènes est une voie métabolique quantitativement importante au cours de la grossesse humaine (Diczfalusy, 1969). Les données concernant le Cobaye sont contradictoires. Chez la femelle non gravide ou chez le mâle, une synthèse d'œstriol n'a pas pu être mise en évidence in vivo par Stoa et Borjesson, 1971, à partir d'œstradiol-17ß et par Quamme, Layne et Williamson, 1972, en perfusant des foies isolés avec de l'œstrone. Cependant, dans une série d'études in vitro en incubant des coupes de foie obtenues à partir de femelles gravides ou non (Hobkirk, Nilsen et Jennings, 1975 ; Hobkirk ef Nilsen, 1977) ou des microsomes hépatiques obtenus à partir de femelles vierges (Harvey et Hobkirk, 1977), une $16 \alpha$ et une 16ßhydroxylation des œstrogènes ont été montrées. Certains d'entre nous (Adessi et al., 1977), en incubant des coupes de foie de femelles gravides avec de l'œstrone ou de l'œstradiol-17 $\beta$, ont montré une synthèse d'cestriol qui est cependant quantitativement 
faible puisque l'œstriol ne représente que moins de 2 p. 100 des œstrogènes isolés. In vivo, Hobkirk, Nilsen et Mori (1978) ont mis en évidence, en utilisant des Cobayes femelles vierges, que la 16-hydroxylation est plus importante pour le sulfate d'œstrone que pour l'œstrone. Comme ces deux œstrogènes sont synthétisés, in vitro, à partir de testostérone ef d'androstènedione par le placenta (Adessi, ef al., 1978) nous nous proposons d'étudier in vitro, le rôle des ovaires maternels et des viscères fotaux dans le métabolisme des œstrogènes produits par le placenta en considérant plus particulièrement la biosynthèse d'œstriol et d'œstradiol-17 $\beta$ ainsi que la conjugaison des cstrogènes.

\section{Matériel ef méthodes.}

Stéroïdes. - Les stéroïdes suivants proviennent de chez Steraloids (Inc., USA) : cstrone $\left(E_{1}\right)$ : 3-hydroxy-1,3,5 (10)-estratrien-17-one ; œstradiol-17 $\beta\left(E_{2}\right): 1,3,5(10)$ estratriène-3,17 $\beta$-diol ; œstradiol-17 $\alpha\left(E_{2}-17 \alpha\right): 1,3,5$ (10)-estratriène-3,17 $\alpha$-diol ; œstriol $\left(E_{3}\right): 1,3,5(10)$-estratriène-3, 16 $\alpha, 17 \beta$-triol ; 16-épi-œstriol (16-épi- $\left.E_{3}\right): 1,3,5(10)$ estratriène-3,16 $\beta, 17 \beta$-triol ; 16 $\alpha$-hydroxyœstrone $\left(16 \alpha-\mathrm{OH}-\mathrm{E}_{1}\right): 3,16 \alpha$-dihydroxy-1,3,5 (10)-estratrien-17-one ; 16-oxo-œstradiol (16-oxo- $\left.\mathrm{E}_{2}\right)$ : 3,17 $\beta$-dihydroxy-1,3,5 (10)œstratrien-16-one ; épicoprostanol : $5 \beta$-cholestan-3 $\alpha$-ol. Après cristallisation leur pureté a été contrôlée par chromatographie sur couche mince (CCM).

La $\left[7 n-{ }^{3} \mathrm{H}\right]$-testostérone (17 $\beta$-hydroxy-4-androsten-3-one) $(16 \mathrm{Ci} / \mathrm{mmol})$ provient de New England Nuclear. Elle a été purifiée par CCM avant chaque utilisation.

Chromatographie sur couche mince (CCM). - La CCM a été effectuée selon Lisboa et Diczfalusy, 1962, en utilisant les systèmes :

1) acétate d'éthyle/cyclohexane (1:1) (Rf. : $E_{1}: 0,59 ; E_{2}: 0,41$ )

2) chloroforme/éthanol (95:5) (Rf. : $E_{1}: 0,46 ; E_{2}: 0,30$ ).

Mesure de la radioactivité. - La radioactivité a été mesurée à l'aide d'un compteur à scintillation liquide Packard Tri-Carb 3003. Le "quenching » a été déterminé par la méthode de standard externe. Le rendement pour le tritium était de 25 p. 100.

Animaux ef incubation. - Des femelles gravides de Cobayes albinos de souche Hartley $(700$ à $900 \mathrm{~g}$ ) ont été sacrifiées par décapitation durant les deux dernières semaines de gestation (50 à 64 jours après le coït). Les différents tissus maternels et fœatax ont été immédiatement prélevés et lavés à $+4^{\circ} \mathrm{C}$ dans une solution de $\mathrm{NaCl}$ à 0,9 p. $100(p / v)$.

Différentes séries de 6 incubations ont été effectuées. Elles renfermaient : a) un placenta $(P) ; b$ ) les 2 ovaires maternels $(O) ; c)$ un placenta et 2 ovaires maternels $(P+O)$ et $d)$ un placenta et les viscères fœtaux, c'est-à-dire un hémi-poumon, un hémi-foie, un hémi-cœur, un rein et une surrénale $(P+F)$. Tous ces tissus ont été finement hachés aux ciseaux ef les incubations ont été réalisées dans $7,5 \mathrm{ml}$ de solution de Krebs-Ringer phosphate $\mathrm{pH} \mathrm{7,00} \mathrm{renfermant} 110 \mu \mathrm{mol}$ de glucose et $10 \mu \mathrm{mol}$ d'ATP (Sigma), sans autres cofacteurs. La [ $\left.{ }^{3} \mathrm{H}\right]$ testostérone à raison de $22 \times 10^{6} \mathrm{dpm}$ dans $20 \mu$ l de propylène glycol a été ajoutée dans chaque fiole. Les tissus ont été incubés pendant 3 heures sous atmosphères $\mathrm{d}^{\prime} \mathrm{O}_{2} / \mathrm{CO}_{2}(95: 5)$. La durée des incubations a 
été fixée au cours d'une étude préliminaire qui a montré que l'équilibre métabolique était atteint entre la $2^{\mathrm{e}}$ et la $3^{\mathrm{e}}$ heure d'incubation. Pour chaque série, un témoin constitué des mêmes tissus et de la même quantité de $\left[{ }^{3} \mathrm{H}\right]$ testostérone a été préparé dans les mêmes conditions et placé immédiatement à $-18^{\circ} \mathrm{C}$.

Extraction et isolement des astrogènes. - Après incubation, 4 volumes d'éthanol absolu ont été ajoutés dans chacune des fioles qui ont été ensuite placées à $-18^{\circ} \mathrm{C}$ pendant $12 \mathrm{~h}$. Après centrifugation et lavage du culot par deux fois 2 volumes d'éthanol à 80 p. 100, les phases éthanoliques ont été rassemblées et évaporées à sec (fraction éthanolique). Chaque résidu a été dissous dans $10 \mathrm{ml}$ d'eau ef extrait par trois fois $10 \mathrm{ml}$ d'éther. Ces phases éthérées ont été rassemblées et évaporées. Chaque résidu a été dissous dans $10 \mathrm{ml}$ d'eau et extrait par trois fois $10 \mathrm{ml}$ d'éther. Ces phases éthérées ont été rassemblées et évaporées à sec. Elles constituent la fraction des œstrogènes non conjugués. Les œstrogènes hydrosolubles ou conjugués restant dans la phase aqueuse ont été hydrolysés à $\mathrm{pH}$ 4,8 par $0,2 \mathrm{ml}$ de suc d'Hélix pomatia (IBF Gennevillier, France) pendant $16 \mathrm{~h}$ à $45^{\circ} \mathrm{C}$ et extrait par trois fois $10 \mathrm{ml}$ d'éther. Les phases éthérées ont éfé évaporées à sec. Elles constifuent la fraction des œstrogènes conjugués. Les œstrogènes de chacune de ces deux fractions ont été purifiés sur colonne de Dowex AG1-X2 (Adessi et al., 1975). Dans les éluats contenant les œstrogènes, $10 \mu \mathrm{g}$ de chacun des différents étalons suivants ont été ajoutés : œstrone, œstradiol-17 $\beta$, œstradiol-17 $\alpha$, $16 \alpha$-hydroxy-œstrone, 16-oxo-œstradiol, œstriol ef 16-épioestriol, puis les œstrogènes ont été isolés par chromatographie sur couche mince bidimensionnelle dans les systèmes 1 et 2 . Les zones radioactives correspondant aux différents œstrogènes, repérées par rapport à des étalons ayant migré simultanément, ont été éluées. Pour chaque éluat la radioactivité a été mesurée sur une fraction aliquote de $1 / 10$; le reste, lorsque la radioactivité étail suffisante a été additionnée de $10 \mathrm{mg}$ de l'œstrogène correspondant puis identifié par le test de cristallisations successives dans le système éthanol/ hexane.

\section{Résultats.}

Les résultats ont été calculés déductions faites des incubations témoins.

Pour l'ensemble des incubations, le pourcentage moyen de la radioactivité récupérée dans les fractions éthanoliques par rapport à celle incubée à été de 77 p. 100 (extrêmes : 62,1-87,9 p. 100). Cette récupération a été calculée sur une partie aliquote de chaque fraction éthanolique.

L'œstrone ef l'œstradiol-17 $\beta$ isolés par CCM ont été identifiés par dilution isotopique inverse. Après incubation des ovaires maternels, ces deux œstrogènes n'ont été identifiés que dans la fraction conjuguée. Pour les autres types d'incubations, ces deux œstrogènes ont été identifiés aussi bien dans les fractions non conjuguées que conjuguées. Le tableau 1 ( $a$ et $b$ ) rassemble ces résultats. L'œstriol n'a pas pu être identifié dans les incubations d'ovaires, de placenta ou de placenta avec les ovaires maternels. Cependant, pour deux des six incubations de placenta avec les viscères fœłaux, il a été identifié à partir des fractions conjuguées. La radioactivité totale de la fraction œstriol est très faible puisqu'elle ne représente que 0,04 p. 100 des deux frac- 
TABLEAU $1 a$

Incubation de ${ }^{3} \mathrm{H}$-testostérone en présence de divers tissus foetaux

Activité spécifique $(\mathrm{dpm} / \mathrm{mg})$ de l'oestrone $\left(E_{1}\right)$ et de l'oestradiol $\left(E_{2}\right)$ isolés après C.C.M. à partir de la fraction libre, système de cristallisation éthanol/hexane $-(C=$ cristal ; $L M=$ liqueur Mère $)$.

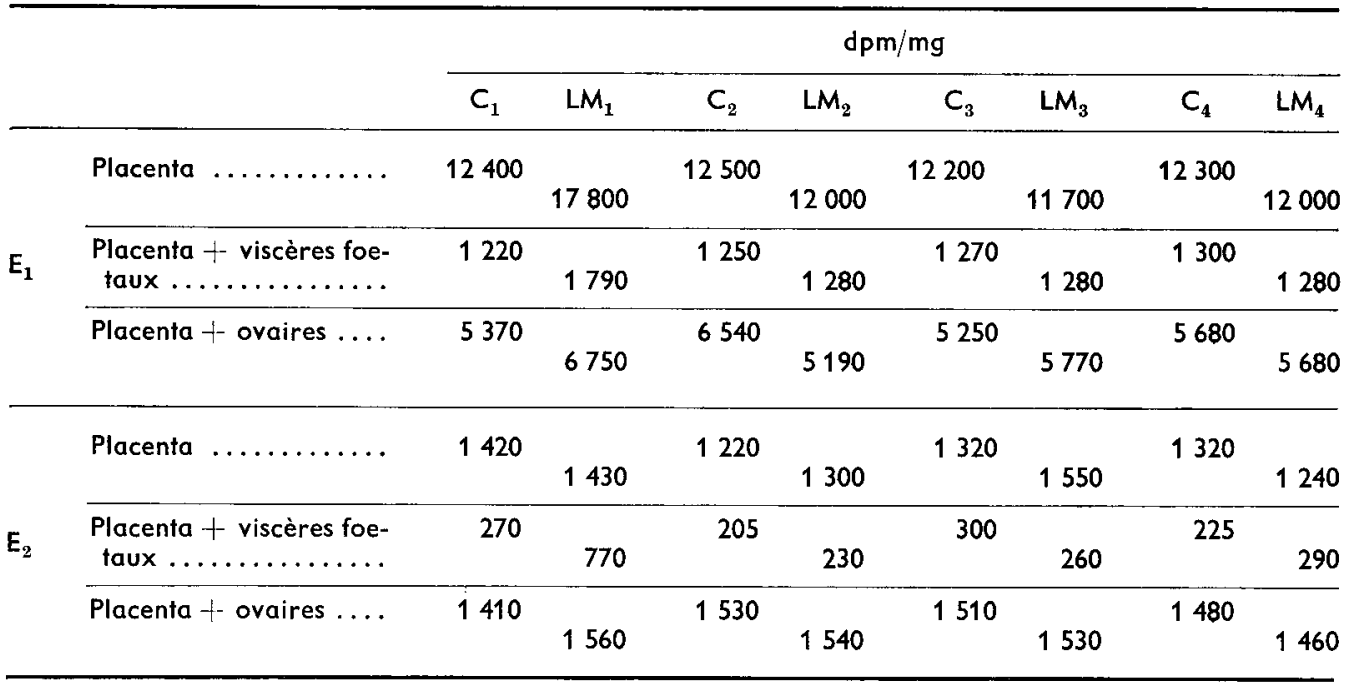

\section{TABLEAU $1 b$}

Incubation de ${ }^{3} \mathrm{H}$-testostérone en présence de divers tissus de cobaye

Activité spécifique $(\mathrm{dpm} / \mathrm{mg})$ de l'oestrone $\left(E_{1}\right)$ de l'oestradiol-17 $\beta\left(E_{2}\right)$ et de l'oestriol $\left(E_{3}\right)$ isolés après C.C.M. à partir de la fraction conjugués, système de cristallisation éthanol/hexane $(C=\mathrm{cristal} ; \mathrm{LM}=$ liqueur Mère).

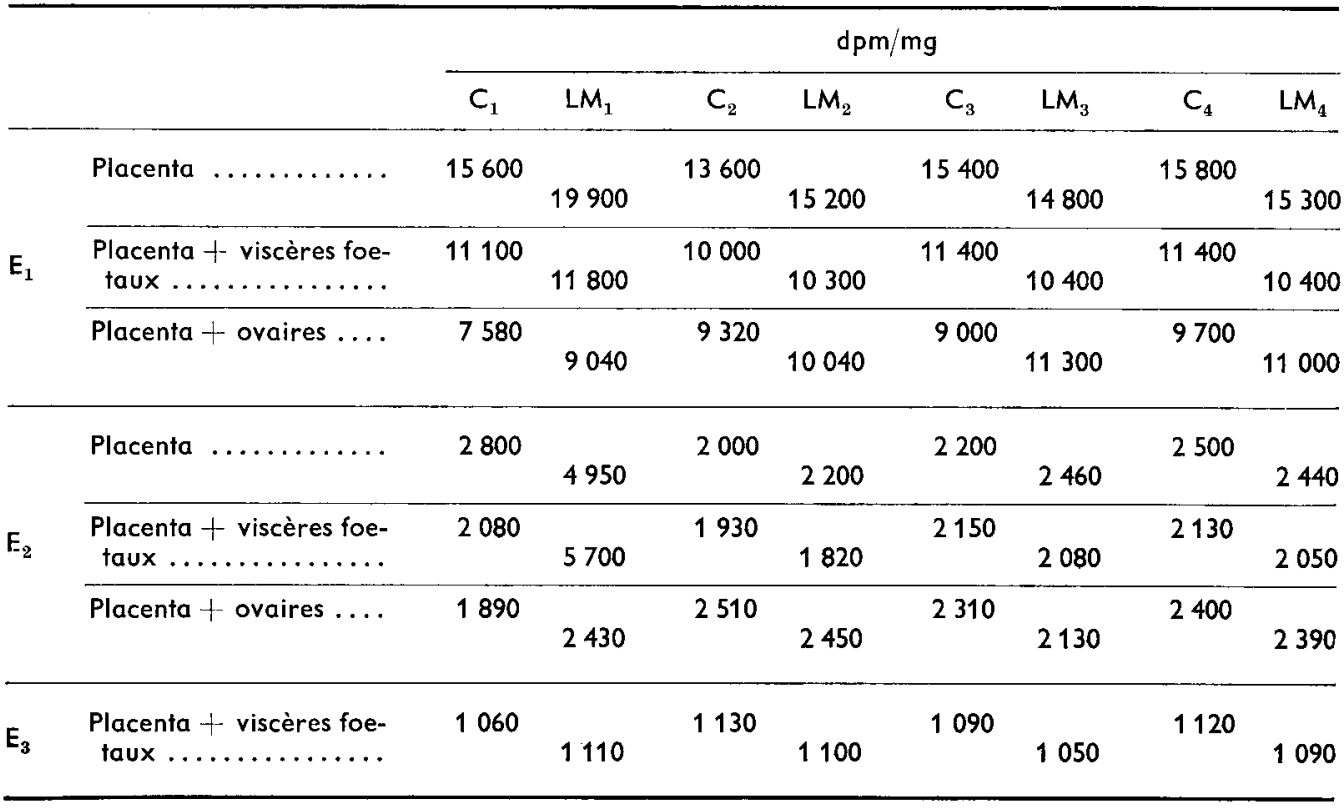




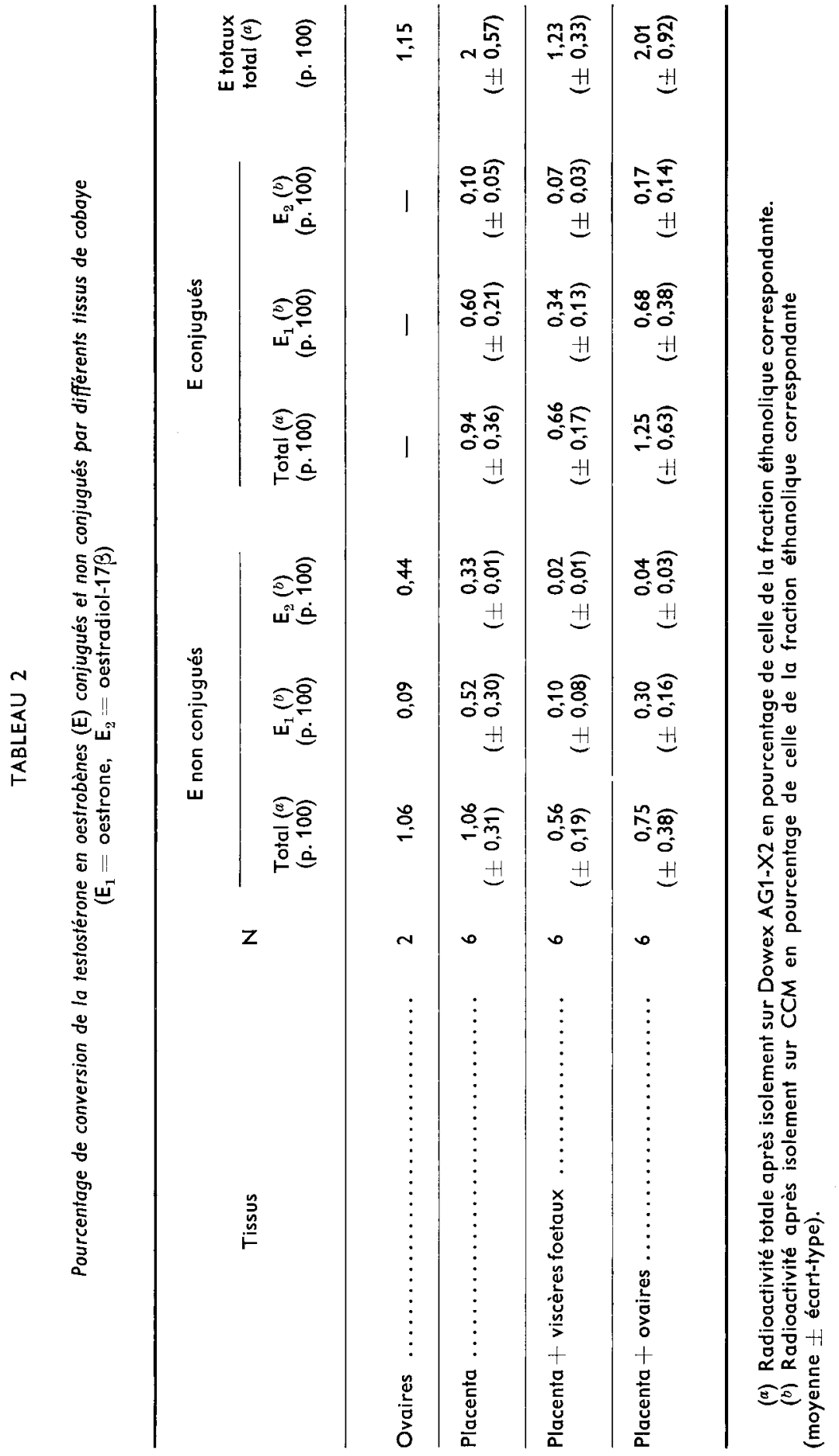


tions éthanoliques correspondantes. Aussi il n'en est pas tenu compte dans les calculs suivants car la moyenne pour les 6 incubations serait de l'ordre de 7 p. 1000.

Les taux de conversion de la testostérone en œstrogènes appréciés en exprimant le pourcentage moyen de la radioactivité des fractions œstrogéniques isolées après passage sur Dowex AG1-X2 par rapport à celle des fractions éthanoliques correspondantes sont rapportées sur le tableau 2. En utilisant le test de Student-Fischer pour apprécier la probabilité $p$ que les résultats diffèrent de façon significative il peut être observé que les pourcentages de conversion de la testostérone en œstrogènes totaux $(p<0,02)$ et en œstrogènes totaux non conjugués $(p<0,01)$ sont plus élevés pour les placentas seuls que pour les placentas avec les viscères fœtaux. Les autres différences ne sont pas significatives. Les pourcentages de conversion de la testostérone en œstrone ef en œstradiol-17 $\beta$ après isolement par CCM sont rapportés aussi sur le tableau 2. La différence entre le total et la somme $E_{1}+E_{2}$ s'explique par le rendement de l'étape de CCM $(55 \pm 10$ p. 100) sauf pour les incubations avec le placenta et les viscères fœetaux dont le faible rendement pourrait être en rapport avec la présence d'autres stéroïdes de grande polarité non identifiés. Ainsi est mis en évidence une plus grande conversion de la testostérone en œstrone non conjugué $(p<0,01)$ et conjugué $(p<0,05)$ après incubation de placenta qu'après incubation de placenta avec les viscères fœtaux. Il existe de même une plus grande conversion en œstrone non conjugué $(p<0,05)$ après incubation de placenta avec les ovaires qu'après incubation du placenta avec les viscères fœtaux. A l'exception des incubations des ovaires maternels pour lesquelles il existe une plus grande synthèse d'œstradiol que d'œstrone $\left(\frac{E_{1}}{E_{2}}=0,21\right)$ tous les autres types d'incubations montrent une plus grande synthèse d'œstrone (tabl. 3). L'étude du rapport $\frac{E_{1}}{E_{2}}$ (non-conjugué) permet de constater qu'il est plus élevé $(p<0,05)$ après incubation avec du placenta seul qu'après incu-

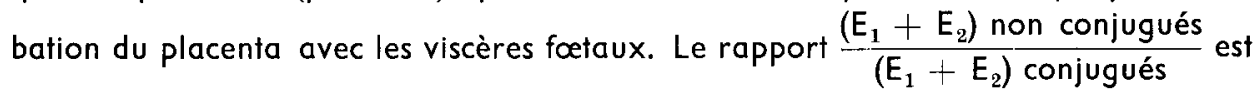
de $0,81 \pm 0,35$ pour des incubations du placenta seul, de $0,32 \pm 0,24$ pour celles du

TABLEAU 3

Etude du rapport $\frac{\text { Oestrone }}{\text { Oestradiol-17ß }}\left(\frac{\mathrm{E}_{1}}{\mathrm{E}_{2}}\right)$ après incubation de testostérone avec différents tissus de cobaye

\begin{tabular}{cccc}
\hline & $\begin{array}{c}\text { Oestrogènes totaux } \\
E_{1} / E_{2}\end{array}$ & $\begin{array}{c}\text { Oestrogènes non conjugués } \\
E_{1} / E_{2}\end{array}$ & $\begin{array}{c}\text { Oestrogènes conjugués } \\
E_{1} / E_{2}\end{array}$ \\
\hline Placenta $\ldots \ldots \ldots$ & $9,26 \pm 4,04$ & $16,18 \pm 7,59$ & $6,65 \pm 2,41$ \\
\hline $\begin{array}{l}\text { Placenta }+ \text { viscè- } \\
\text { res foefaux } \ldots \ldots\end{array}$ & $5,56 \pm 1,70$ & $6,88 \pm 3,73$ & $5,11 \pm 1,64$ \\
\hline $\begin{array}{l}\text { Placenta }+ \text { ovai- } \\
\text { res } \ldots \ldots \ldots \ldots\end{array}$ & $7,52 \pm 5,81$ & $8,54 \pm 3,64$ & $7,98 \pm 8,04$ \\
\hline
\end{tabular}

(Moyenne de 6 incubations \pm un écart-type). 
placenta avec des viscères foetaux et de $0,40 \pm 0,28$ pour celles du placenta avec les ovaires. Ce rapport est plus élevé de façon significative $(p<0,02)$ pour les incubations du placenta seul que pour les incubations du placenta avec les viscères fœetaux. Les différences observées avec les incubations du placenta avec les ovaires ne sont pas significatives.

\section{Discussion.}

Au cours de cette étude in vitro, en présence de testostérone, il n'a pas été observé de différences significatives entre les résultats obtenus après incubations du placenta seul et ceux obtenus après incubation simultanée du placenta et des ovaires maternels. Cependant, l'incubation d'ovaires seuls conduits à la synthèse prédominante d'cestradiol-17 $\beta$ non conjugué, tandis que l'incubation du placenta seul conduit à la synthèse prédominante d'œstrone conjuguée et non conjuguée. Comme l'incubation simultanée d'ovaires et de placenta conduit aux mêmes composés que lors de l'incubation de placenta seul, il est possible de conclure que l'activité de conjugaison placentaire prédomine ainsi que la transformation du type placentaire de l'œstradiol-17 $\beta$ en œstrone.

L'étude du rapport $\frac{E_{1}+E_{2} \text { (non conjugués) }}{E_{1}+E_{2} \text { (conjugués) }}$ montre l'existence d'une conjugaison fœtale des œstrogènes puisque ce rapport est plus faible de façon significative après incubation de placenta et de viscères fœtaux $(0,32)$ qu'après incubation de placenta seul $(0,81)$. La synthèse d'œstrogènes conjugués par le placenta et le foetus pose la question de leur rôle physiologique. Il peut s'agir là d'un mécanisme de régulation du taux intra-fœtal des œstrogènes libres puisqu'il n'existe pas de protéine plasmatique de transport des œstrogènes chez le Cobaye (Plapinger et al., 1977).

L'activité de la 17ß-hydroxystéroïde-oxidoréductase peut être appréciée par l'étude du rapport $\frac{E_{1}}{E_{2}}$. Comme nous l'avons déjà mentionné elle favorise dans nos conditions expérimentales la formation d'œstradiol-17 $\beta$ dans les ovaires et au contraire d'œstrone dans le placenta. Cependant, cette production ovarienne d'œstrogènes ne semble pas avoir un rôle important in vivo puisque l'ovariectomie bilatérale de la mère après 40 jours de gestation n'entraîne pas de diminution significative des œstrogènes plasmatiques (Challis, Heap et Illingworth, 1971). Il est donc possible d'envisager que la majorité des œstrogènes synthétisés par le Cobaye durant la gestation proviennent du placenta et des fœutus. Chez ces derniers, nous avons montré qu'il existait une synthèse relativement plus grande d'œstradiol-17 $\beta$ que d'œstrone dans la fraction non-conjuguée favorisant ainsi la formation du seul ostrogène pour lequel existe des récepteurs cellulaires fœtaux (Pasqualini, Sumida et Gelly, 1976 ; Plapinger et al., 1977).

Les incubations simultanées de placenta et des viscères fœtaux ont permis de montrer pour deux d'entre-elles une synthèse d'œstriol. Cependant, la très faible radioactivité liée à ce composé ne permet pas de conclure qu'il existe, in vitro, chez le fœtus une importante activité $16 \alpha$-hydroxylasique.

Challis ef Illingworth en 1972 ont constaté à l'inverse après injection in vivo 
d'androstènedione une synthèse importante d'œstriol. Une conclusion définitive sur la synthèse de ce composé par le fotus est difficile a proposer éfant donné les conditions expérimentales différentes utilisées pour ces expérimentations.

Ce problème se complique du fait que ces derniers auteurs n'ont pas précisé la souche de Cobaye utilisée. En effet, Hobkirk et al. $(1975,1977,1978)$ et Harvey ef Hobkirk (1977) qui ont mis en évidence une hydroxylation en $16 \propto$ ou $16 \beta$ des œstrogènes, ont utilisé des Cobayes de souche «English Shorthair », tandis que nous avons utilisé une souche albinos « Hartley ». Nous pensons qu'il s'agit là d'un point fondamental ef nous nous proposons de continuer nos travaux sur la synthèse fœtale de l'œstriol en utilisant différentes souches de Cobaye.

Reçu en mars 1979. Accepté en mai 1979.

\section{Références}

ADESSI G., EICHENBERGER D., TRAN QUANG NHUAN., JAYLE M. F. 1975. Gas chromalography profile of estrogens : application to pregnancy urine. Steroids, 25, 553-564.

ADESSI G., GOUTTE-COUSSIEU C., TRAN QUANG NHUAN, JAYLE M. F., 1977. Métabolisme in vitro, de la $6,7-{ }^{3} \mathrm{H}$ estrone et du $6,7 \cdot{ }^{3} \mathrm{H}$ ostradiol par le foie de cobaye gestant. $C$. $R$. Soc. Biol., 171, 20-27.

ADESSI G., GOUTTE-COUSSIEU C., TRAN QUANG NHUAN., EICHENBERGER D., JAYLE M. F., 1978. Conversion, in vifro, de la $7 n-{ }^{3} \mathrm{H}$ testosterone to estrone and estradiol $17 \beta$ and their 3-sulfate conjugate by the guinea-pig placenta. Steroids, 32, 295-306.

CHALLIS J. R. G., HEAP R. B., ILLINGWORTH D. V., 1971. Concentrations of œstrogens and progesterone in the plasma of non pregnant, pregnant and lactating guinea-pig. J. Endocr., 51, 333-345.

CHALLIS J. R. G., ILLINGWORTH D. V., 1972. Oestrogens in the pregnant guinea-pig.J. Reprod. Fert., 31, 504-505.

DICZFALUSY E., 1969. Steroid metabolism in the foto-placental unit, 65-109. In PECILE A. FINZI C., The foeto-placental unit. Excerpta med. Found., Amsterdam.

HARVEY P. R. C., HOBKIRK R., 1977 . The metabolism of estrone and estradiol-17 $\beta$ and their 3-sulfates by female guinea-pig liver microsomes. Steroids, 30, 115-128.

HOBKIRK R., NILSEN M., JENNINGS B., 1975. Evidence for $16 \alpha$-hydroxylation of estrone 3-sulfate by guinea-pig liver slices. Can. J. Biochem., 53, 1133-1135.

HOBKIRK R., NILSEN M., 1977. Evidence for 16/-hydroxylation of estrogens by guinea-pig liver slices. Can. J. Biochem., 55, 769-771.

HOBKIRK R., NILSEN M., MORI J., 1978. 16-hydroxylation of estrone-3-sulfate and estrone in the guinea-pig in vivo. Endocrinology, 103, 1227-1133.

LISBOA B. P., DICZFALUSY E., 1962. Separation and characterisation of steroid oestrogens by means of thin-layer chromatography. Acta endocr. (Kbh), 40, 60-81.

PASQUALINI J. R., SUMIDA C., GELLY C., 1976. Cytosol and nuclear ${ }^{3} \mathrm{H}$ oestradiol binding in the foetal tissues of guinea-pig. Acta endocr. (Kbh), 83, 811-828.

PLAPINGER L., LANDAU I. T., MCEWEN B. S., FEDER H.H., 1977. Characteristics of estradiol-binding-macromolecules in fetal and adult guinea-pig brain cytosols. Biol. Reproduc., 16, 586-599.

QUAMME G. A., LAYNE D. S., WILLIAMSON D. G., 1972. The metabolism of ${ }^{3} \mathrm{H}$-labelled estrone by the isolated perfused liver of the rabbit, chicken and guinea-pig. Can. J. Physiol. Pharmacol., 50, 45-47.

STOA K. F., BORJESSON B. W., 1971. Metabolism of oestradiol-17 $\beta$ in the guinea-pig. Biochim. biophys. Acta, 239, 337-344. 